MATEC Web of Conferences 53, 01054 (2016)

DOI: $10.1051 /$ matecconf/20165301054

(C) Owned by the authors, published by EDP Sciences, 2016

\title{
Wavelet analysis function of changing average work amounts in monolithic construction
}

\author{
Tatiana Simankina ${ }^{1}$, Marina Romanovich ${ }^{2,}$ a and Oleg Tsvetkov ${ }^{3}$ \\ ${ }^{1}$ Peter the Great Saint-Petersburg Polytechnic University, Russia, 195251, St. Petersburg, Polytechnicheskaya St., \\ 29 \\ ${ }^{2}$ State unitary enterprise "Municipal government of inventory and assessment of real estate", Russia, 191104, St. \\ Petersburg, Belinskogo St., 13 \\ ${ }^{3}$ Federal state budgetary educational institution of higher professional education "Komsomolsk-on-Amur state \\ technical University" ("KnASTU"), Russia, 681013, Khabarovsk, Lenin prospect, 27
}

\begin{abstract}
In work periodicity of impact of various external and internal factors on function of changing average work amounts and extent of various factors influence on the process of monolithic construction are defined by wavelet transform. Basic data are data on daily amount of the concreted structures (CBM) in 4.5 months. Using the continuous wavelet transform wavelet spectrum was constructed, which showed the periods of impact of external and internal factors on the construction process. Using the discrete wavelet transform the algorithm of an exception of critical deviations from a function of changing average work amounts was developed. This algorithm allows to plan future works taking into account the revealed factors.
\end{abstract}

\section{Introduction}

Many scientific papers are dedicated to the analysis of various phenomena and processes using wavelet transforms [1-14]. For example, in the field of research of social processes [6], in the study of patterns of signals in radio electronics $[7,8]$ in the context of manufacturing processes for prediction of injuries [9], in the prediction of climate and weather conditions, studies of seismic effects [4, 10, 12], to predict the technological characteristics of industrial production [11], and also in the medical field to detect various abnormalities occurring in the human body, for the processing of digital images, in the fields of physics, chemistry, etc. However, in the field of analysis and prediction of different characteristics of the construction process, the wavelet transform is not widely used.

In a general view the formula of the wavelet transform:

$$
\psi_{a b}(t)=\frac{1}{\sqrt{a}} \psi\left(\frac{t-b}{a}\right)
$$

where $\psi_{a b}(t)$ - wavelet, defined for the set parameters $a$ and $b$, generated by a maternal initial wavelet $\psi(t)$;

$b$ - shift parameter in time;

$a$ - parameter of time scale change (levels of detail);

$1 / a^{\wedge} 1 / 2$ - the multiplier providing independence of norm of functions from the value $a$.

\footnotetext{
${ }^{\text {a }}$ Corresponding author : p198320@yandex.ru
} 
Small values of a correspond to small scale $\psi a b(t)$ or at higher frequencies where $\omega \sim 1 / a$. Large values of parameter $a$ correspond to large scale $\psi a b(t)$ and low frequencies. Due to the change of scale, wavelets are able to identify the difference in characteristics at different frequencies. By shifting wavelets are able to analyze the properties of the signal at different points throughout the studied interval. Therefore in the analysis of the signals created by a number of data, the wavelet transform is a significant advantage over Fourier transform. The Fourier transform gives a global information about the frequencies of the analyzed signal when used at system of functions defined on infinite intervals.

\section{Data description and methology}

The analysis of data on daily average amounts of work performed in the construction of monolithic house was carried out. Basic data are data on daily amount of the concreted structures (CBM) in 4.5 months (October, November, December, January, February).

Average daily amounts are calculated by the formula:

$$
V_{\text {averagei }}=V_{d i}+\frac{V_{s t}}{N_{t}}
$$

where $V_{\text {averagei }}$ is the average amount of work performed in the $i$-th day, CBM;

$V_{d i}$ - the volume of the concrete designs (walls, columns), etc. in the $i$-th day, cubic meters, CBM;

$V_{s t}$ - the volume of concrete section of slab for the period of time $t$;

$N_{t}$ - number of the working days in the period of time $t$.

Time period $t$ is the number of days between the concreting sections of floor slabs. The function of changing average work amounts was made using the calculated values of the average daily amount of work performed in each day of the reporting period (4.5 months).

The function of change in average amounts was investigated using continuous wavelet transform and discrete wavelet transform.

Continuous wavelet transform may be direct and reverse. Direct continuous wavelet transform is defined by a formula (3), reverse continuous wavelet transform is defined by a formula (4).

$$
\begin{gathered}
W_{S}(a, b)=\left(f(t), \psi_{a b}(t)\right)=\frac{1}{\sqrt{a}} \int_{-\infty}^{+\infty} f(t) \psi\left(\frac{t-b}{a}\right) d t \\
f(t)=\frac{1}{C_{\psi}} \int_{-\infty}^{+\infty} \int_{-\infty}^{+\infty} W_{S}(a, b) \psi_{a b}(t) \frac{d a d b}{a^{2}}
\end{gathered}
$$

where $C_{\Psi}$ - the normalizing coefficient:

$$
C_{\Psi}=\int_{-\infty}^{+\infty}|\Psi(\omega)|^{2}|\omega|^{-1} d \omega \angle \infty
$$

where $(\cdot, \cdot)$ - scalar product of the corresponding factors,

$\Psi(\omega)$ - Fourier transform of a wavelet $\psi(t)$.

The wavelet spectrum $W_{s}(a, b)$ or scale-time spectrum is a function of two arguments - parameter of time scale change $a$ and shift parameter in time $b$. Spectrum $W s(a, b)$ is a surface in threedimensional space. However, as a rule, instead of the image of a surface spectrum represents it's projection to the $a b$ plane. It is also possible to analyze pictures of lines of local extrema (maxima) of these surfaces, so-called skeleton which helps to reveal structures of the analyzed initial signal [15].

It is necessary to perform many computing operations for calculation of a wavelet spectrum at continuous change of parameters $a$ and $b$. Many functions $\psi_{a b}(t)$ are redundant. It is necessary to conduct the discretization of these parameters at preservation of possibility of restoration of a signal from its transformation. Discretization is usually carried out for constructions of number two in degree [17-19].

Let $a=2 \mathrm{~m}, b=\mathrm{k} \cdot 2 \mathrm{~m}$, then the expression (1) takes the following form: 


$$
\psi_{m k}(t)=\frac{1}{\sqrt{a}} \psi\left(\frac{t-b}{a}\right)=\frac{1}{\sqrt{2^{m}}} \psi\left(2^{-m} t-k\right)
$$

where $m$ и $k$ - integers.

Thus earlier considered $a b$ plane turns into the corresponding grid of $m, k$. Direct and reverse wavelet transform will be determined by formulas:

$$
\begin{gathered}
c_{m k}=\left(f(t), \psi_{m k}(t)\right)=\int_{-\infty}^{+\infty} f(t) \psi_{m k}(t) d t, \\
f(t)=\sum_{m, k} c_{m k} \psi_{m k}(t)
\end{gathered}
$$

Drawing an analogy with the Fourier transform, the coefficients $c_{m k}$ can be determined using continuous wavelet transform $W s(a, b)[15]$ :

$$
c_{m k}=W\left(2^{m}, k \cdot 2^{m}\right)
$$

Thus, from the formula (8) shows that the basic signal $f(t)$ can be represented as the sum of «wavelet waves» with defined coefficients $c_{m k}$.

\section{The results of wavelet analysis}

To study the function of changes in average amounts of work discrete approximation of Meyer wavelet ("dmey") was used, and 14-th approximation of the studied function [16]. In Figure 1 some schedules are submitted:

a) 14-th approximation of function of changes in average amounts of work;

b) the wavelet spectrum $W(a, b)$ coefficients as projections on the $a b$ plane (parameter of time scale change, shift parameter in time). In any point of the plane it is possible to determine the frequency corresponding to a certain value of coefficients $a$ and $b$. Color shows the value of the spectrum $W(a, b)$ on the module. Light areas correspond to great values coefficients, dark tone fixes transitions of a signal through zero. In our case average value of a signal is accepted to zero. Shades of gray-brown flowers in each area allocated ranges of transitional values of the wavelet spectrum $W(a, b)$;

c) for example values of the wavelet spectrum $W(a, b)$ which correspond to scale $a=32$ are shown;

d) shows the wavelet spectrum $W(a, b)$ with well-defined lines of local maxima, passing approximately in the middle of light areas of the plane $a b$ graphics $b$ ).

The larger the scale of the wavelet, the wider area of the signal will affect the result [9]. Each area of the wavelet spectrum $W(a, b)$ is formed as a result of impact on function of changing average work amounts of these or those factors.

The wavelet spectrum reveals not only the hierarchical structure of the analyzed time series, but also carries information about the processes taking place during the period of construction, in particular about influence of external and internal factors on the progress of construction. Using the analysis of the wavelet spectrum it is possible to find global relationships between different parameters and the influence of some parameters on others, in a certain period of time. Analyzing the alternation of areas with different frequency and how function of changes in average amounts of work is influenced by external and internal factors, it is possible to predict behavior of function. And most importantly, the analysis allows to diagnose and predict unstable conditions and the moments of approach of critical deviations of function.

In the analysis of the wavelet spectrum $W(a, b)$ the lines of local maxima of surfaces presented on graphics of d) Figure 1 were also analyzed.

In table 1 results of the analysis of the wavelet spectrum $W(a, b)$ for the 14th approximation function of changes in average amounts of work and for basic function are given in a period which equals 4.5 months (128 days). Levels of detail $a$ of wavelet -decomposition are specified in the second column of the table, average values of the periods $T$ are shown in the third column, average standard errors of the periods $\sigma T$ are given in the fourth column. 
By comparison of statistical data about construction of the monolithic house to the data presented in table 1 the periods of emergence of various factors influencing the course of construction were determined (table 2).

a)

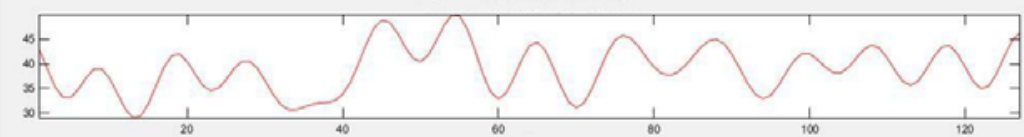

b)

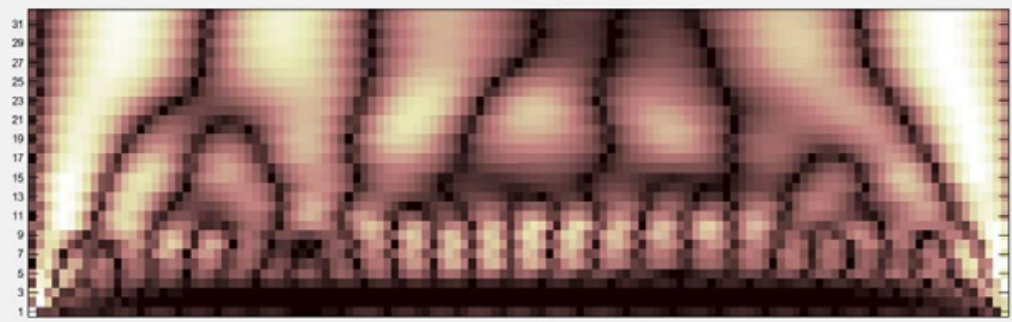

c)

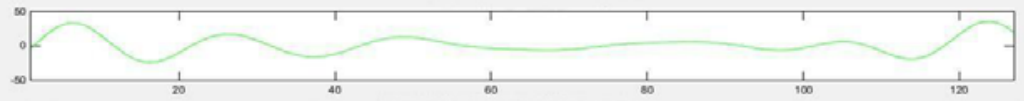

d)

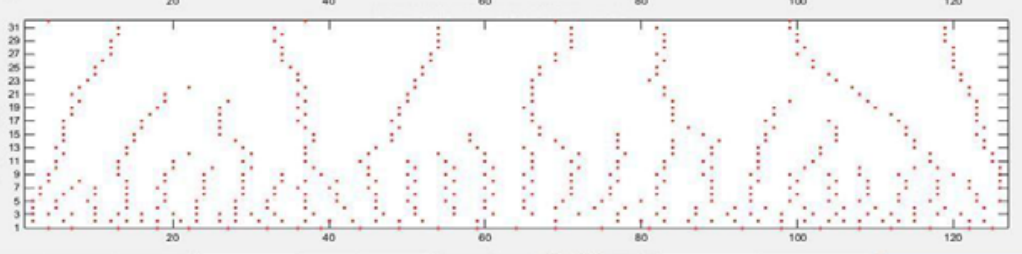

Figure 1. Continuous wavelet transform 14th approximation function of changing average work amounts.

Table 1. Analysis of the wavelet spectrum $W(a, b)$.

\begin{tabular}{|c|c|c|c|}
\hline № & $a$ (levels of detail) & T, days & $\sigma \mathrm{T}$, days \\
\hline \multicolumn{4}{|c|}{ 14th approximation function of changing average work amounts } \\
\hline 1 & 7 & 4 & \pm 1.5 \\
\hline 2 & 15 & 10 & \pm 3.5 \\
\hline 3 & 25 & 19 & \pm 4.5 \\
\hline 4 & from 5 to 25 & 70 & \pm 5.5 \\
\hline \multicolumn{4}{|c|}{ Basic function of changing average work amounts } \\
\hline 5 & 40 & 25 & \pm 4.5 \\
\hline 6 & 61 & 45 & \pm 3 \\
\hline
\end{tabular}

Table 2. The periods of impact of external and internal factors on the progress of construction.

\begin{tabular}{|c|l|c|c|}
\hline № & \multicolumn{1}{|c|}{ Factors } & T, days & $\sigma \mathrm{T}$, days \\
\hline 1 & Failures in work of construction crew & 4 & \pm 1.5 \\
\hline 2 & $\begin{array}{l}\text { The elimination of defects revealed in } \\
\text { the work }\end{array}$ & 10 & \pm 3.5 \\
\hline 3 & De-energization of a building site & 70 & \pm 5.5 \\
\hline 4 & $\begin{array}{l}\text { Delays in supply of construction } \\
\text { materials }\end{array}$ & 25 & \pm 4.5 \\
\hline 5 & Repair of cranes and mechanisms & 45 & \pm 3 \\
\hline 6 & $\begin{array}{l}\text { Non-working condition of cranes and } \\
\text { mechanisms }\end{array}$ & \\
\hline
\end{tabular}

In this work comparison of the latent features of function of changing average work amounts Figure of works was carried out with factors data which were managed to be collected in 4.5 months of construction of the monolithic house. However there could be more factors. Studying of their hidden influences on the course of construction can become separate area for further studying. 
Figure 2 shows the discrete wavelet transformation of function of changing average work amounts for one month of construction works. As the base functions in the decomposition it is used Daubechie's wavelet $(\mathrm{db})$ of the 1 st order. Figure 2 shows the graphic of the function of changing average work amounts $(s / d s)$ and a graphics of the components of the function, restored by the approximating coefficient $a_{4}$ and to the detailing coefficients $d_{1}, d_{2}, d_{3}, d_{4}$. The detailing coefficients show dynamics details at the allocated levels. The coefficient $d_{l}$ is the closest approximation to basic function, $d_{4}$ coefficient - the farthest approximation which shows details of the main trends of the high-frequency component of the time series. The low-frequency filter $a_{4}$ reflects the main tendencies of low-frequency components. The schedule $a_{4}$ shows that the function of changing average work amounts at deep 5-level decomposition reveals two main trends. The first trend - the average amount of completed work during the first 16 days of month equals $44 \mathrm{CBM}$ a day. Further until the end of a month of construction works the main trend performed amount was $40 \mathrm{CBM}$ a day.

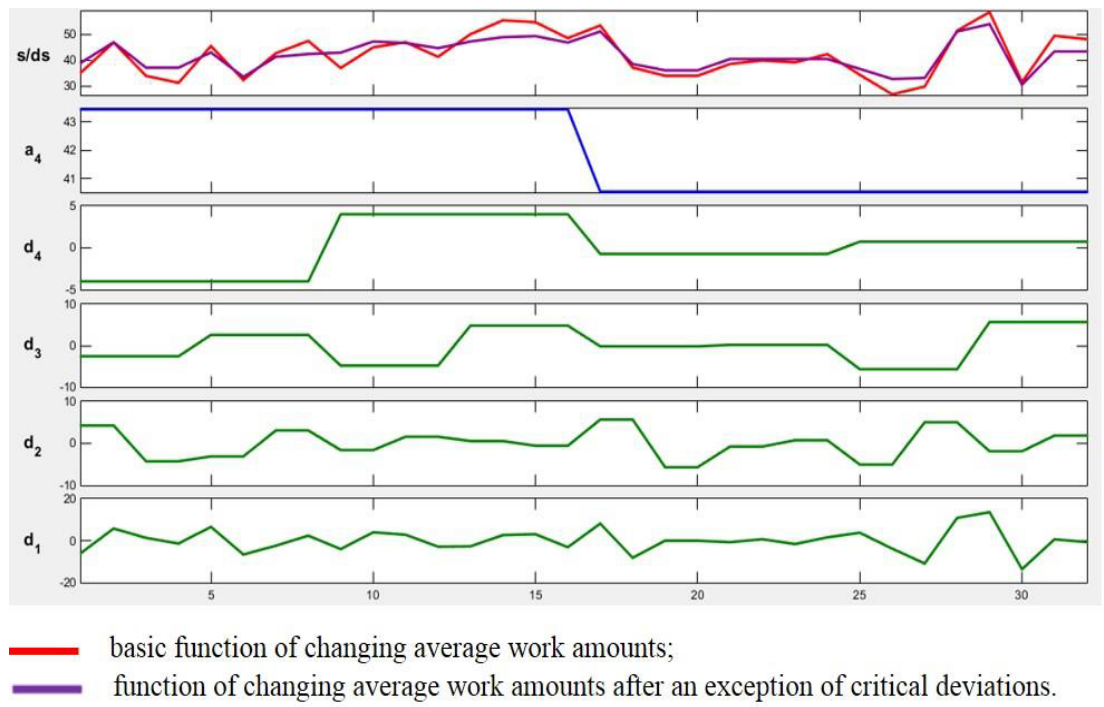

Figure 2. Continuous wavelet transform 14th approximation function of changing average work amounts.

Thus the general regularity of change of the performed works for construction of the monolithic house within one month was revealed. This regularity can't be revealed from basic function.

The algorithm of an exception from function of changing average work amounts critical deviations developed. Deviations arise as a result of the impact on the function of various factors leading to deviations of the function from the given trend. In our case, the given trend is the average value of the daily executed amount of works (CBM of the concreted designs). Deviations from the trend should be minimal, especially in the direction of decreasing values of the average amount of work performed. The algorithm is given below.

1. Formation of a data number for basic function of changing average work amounts. For a start it is necessary to define value of a number of data of function and the studied period (schedule $\mathrm{s}$ in Figure 2).

2.Processing of data series functions. At this stage it is necessary to carry out the analysis of a number of data of function by means of wavelet transforms, to reveal the maximum and minimum deviations of values, to define the factors influencing function and the periods of emergence of factors.

3. Decomposition of basic function of changing average work amounts. It is necessary to choose wavelet, its order and number of levels of decomposition of function $\mathrm{N}$.

4. Threshold processing. For each level from 1 to $\mathrm{N}$ it is necessary to choose thresholds (depending on objectives). After that it is necessary to execute threshold processing of the detailing coefficients 
on those sites of function where it is necessary to minimize or at all to clean the critical deviations of function at all from the set trend resulting from impact on function of various factors.

5. Reconstruction. At the fifth stage of algorithm it is necessary to carry out restoration of values of function by means of the reverse wavelet transform after threshold processing. The result is a function without critical deviations or with the minimum deviations (schedule $d s$ in Figure 2).

6. Scheduling. After an exception or minimization of critical deviations we get a function of changing average work amounts without impact on it of various factors. If we compare basic function and the function after an exception of critical deviations it is possible to define extent of impact of this or that factor on construction process at a specific point in time. If we know frequency and extent of influence of factors on construction process it is possible to change number of workers in this or that day, to correct the schedule of work of crews, to enter additional days of check and setup of machines and mechanisms. These actions will allow to optimize control of daily amount of the performed works and construction.

\section{Conclusion}

Thus frequency and extent of impact of various factors on function of changing average work amounts and the general course of construction can be defined by using the wavelet transforms. The developed algorithm allows to plan future works taking into account the revealed dependences.

\section{References}

1. N. Astaf'eva, Uspekhi fizicheskikh nauk, 11, 1145-1170 (1998).

2. V. G. Zakharov, Razrabotka $i$ primenenie metodov vejvlet-analiza $k$ nelinejnym gidrodinamicheskim sistemam (Istitute of mechanics of continuous environments, Perm', 1997).

3. L. Novikov, Nauchnoe priborostroenie, 3, 70-76 (2000).

4. V. Alekseev, Vestnik Yurskogo gosudarstvennogo universiteta, 3 (30), 3-10 (2013).

5. I. Dremin, O. Ivanov, V. Nechitajlo, Uspekhi fizicheskikh nauk, 5, 465-501 (2001).

6. A. Davydov, Sotsiologicheskie issledovaniya, 11, 89-102 (2003).

7. O. Lazorenko, S. Lazorenko, L. Chernogor, Radiofizika i radioastronomiya, 2, 182-204 (2007).

8. O. Lazorenko, S. Lazorenko, L. Chernogor, Radiofizika i radioastronomiya, 3, 278-294 (2007).

9. N. Muller, S. Seryj, Upravlenie v sotsial'no-ehkonomicheskikh sistemakh, 3 (21), 52 - 60 (2009).

10. V. Mkrtychev, A. Reshetov, Vestnik MGSU, 7, 59 - 67 (2013).

11. A. P. Lushavin, Prognozirovanie kharakteristik tekhnologicheskikh protsessov promyshlennogo proizvodstva $s$ ispol'zovaniem iskusstvennykh nejronnykh setej $i$ vejvlet-preobrazovanij (FGBOU VPO Samarskij gosudarstvennyj tekhnicheskij universitet, Samara, 2012).

12. A. Y. Nikul'nikov, Tekhnologiya interpretatsii rezul'tatov vejvlet-preobrazovaniya sejsmicheskoj zapisi (Rossijskij Gosudarstvennyj Geologorazvedochnyj universitet im. Sergo Ordzhonikidze, Moscow, 2012).

13. O. Amosov, N. Muller, Internet-zhurnal Naukovedenie, 3, 1 - 14 (2014).

14. O. Mandrikova, A. Tiristanov, trudy Vserossijsk. nauchn. konf. Proektirovanie nauchnykh i inzhenernykh prilozhenij v srede Matlab, 242-261 (2002).

15. A. N. Yakovlev, Vvedenie v vejvlet-preobrazovaniy (NGTU, Novosibirsk, 2003).

16. M. Romanovich, Sovremennye problemy nauki i obrazovaniya, 1, URL: http://www.scienceeducation.ru/121-19053 (2015).

17. O. V. Nagornov, V. G. Nikitaev, S. A. Tyuflin, A. N. Pronichev, T. I. Bukharova, K. S. Chistov, R. Z. Kashafutdinov, V. A. Khorkin, Vejvlet-analiz v primerakh (NIYAU MIFI, Moscow, 2010).

18. N. K. Smolentsev, Osnovy teorii vejvletov. Vejvlety v MATLAB (DMK Press, Moscow, 2005).

19. I. Dobeshi, Desyat' lektsij po vejvletam (NITS Regulyarnaya i khaoticheskaya dinamika, Izhevsk, 2001). 